\title{
Study on Quality Index of Distribution Network Planning
}

\author{
Huaiyuan Tian ${ }^{1,}$, , Haibing Zhao ${ }^{1,}$ a, Bing $\mathrm{Li}^{1}$, a , Wenhao Gao ${ }^{1,}$ a and Chenglei \\ Sun $^{2,3, b}$
}

1Dezhou Power Supply Company, State Grid Shandong Electric Power Company, Dezhou 253000, China.

${ }^{2}$ School of Economic and Management, North China Electric Power University, Beijing 102206, China;

2Jinzhou Electric Power Supply Company, State Grid Liaoning Electric Power Supply Co. Ltd, Jinzhou 121001, China.

adzfzchb@163.com, b277129298@qq.com

Keywords: Distribution network, quality index, fish bone, Delphi, fuzzy analytic hierarchy process Abstract: Distribution network planning is to guide the distribution network construction and management of key links, is the global energy Internet construction is an important work. In this paper, the key factors influencing the quality of distribution network are analyzed by using fish bone diagram analysis method, and then the Delphi expert consultation method and fuzzy analytic hierarchy process are used to determine the quality index of distribution network planning. This indicator can not only fully reflect the quality of distribution network planning, but also can carry out longitudinal evaluation and horizontal comparison of the actual situation of distribution network in different regions, find out the weak links of regional distribution network, guide the development of future distribution network direction.

\section{Introduction}

Distribution network construction scale is huge, uncertain factors are complex, involving a wide range, is a complex and difficult systematic project. Therefore, only through the scientific and effective distribution network planning program to determine and implement, in order to correctly grasp the future development of the distribution network. The design and construction of the distribution network planning quality index is imminent in the design of the distribution network planning scheme and the detailed data of the distribution network and the evaluation standard. [1,2]

This paper aims to construct a set of distribution network quality index of the global energy Internet by combining the fish bone map, the Delphi expert consultation theory and the fuzzy analytic hierarchy process, through the actual investigation of the current situation of the regional distribution network planning method, The planning level of the power grid planning, the improvement of the overall evaluation of the distribution network planning is not strong, the adaptability is not strong and the evaluation basis is simple, and the efficiency of the distribution network planning work is improved, which brings better management of the distribution network in the area Economic and social benefits. $[3,4]$

\section{Construction of Distribution Network Quality Index}

\section{Construction principles}

RFID (Radio Frequency Identification), is a kind of communication technology, mainly composed of an electronic tag, reader, middleware, software system of four parts. [5,6] RFID technology can by radio signal to replace the original mechanical or optical contact method to identify specific targets and to read and write the related data, make the information easier to read and write. [7] Because of the RFID technology is more than a lot of advantage (as shown in table 1), RFID technology is widely used in logistics, transportation, factory management, library management, entrance guard system, food safety traceability, etc. 


\section{Selection of Quality Index for Distribution Network Planning}

This paper mainly uses the method of Delphi expert consultation and fish bone map to construct the index type. Process, seek 10 expert advice, statistical processing, and feedback the results of the consultation. After repeated rounds of time, the views tend to focus, and then through the analysis of the elements of fish bone analysis of the relationship between the elements to determine the final type of indicators.

In order to fully reflect the quality of distribution network planning, the impact of primary indicators on the quality of distribution network planning can be summarized into five aspects: power supply capacity, power supply quality, power grid structure, equipment level, power grid efficiency. Power supply capacity level is used to evaluate the power supply enterprises can be long-term, stable and safe to the user's maximum load capacity of the level; power supply quality reflects the power supply service quality of the user is good or bad; grid structure is its voltage level combination, the Level power supply range, the capacity of the transformer configuration and network layout; equipment level of technology describes the advanced nature of the power grid equipment and use; power efficiency level of power companies characterize the economic and profit levels.

\section{Power supply capacity}

Distribution network power supply capacity, marking the grid company for the user's maximum load capacity, is to achieve the premise of the power supply needs and guarantees, an objective reflection of the distribution network planning level. The index is mainly composed of three sub-indicators, respectively, $110 \mathrm{kV}$ power supply capacity, $35 \mathrm{kV}$ power supply capacity and $10 \mathrm{kV}$ power supply capacity. Of which more than $10 \mathrm{kV}$ power grid, transformer capacity ratio, the proportion of heavy-duty lines and heavy load accounted for the main factors affecting the power supply capacity. While the 10-kilovolt power grid, household with variable capacity, medium-pressure heavy-duty line ratio, medium-pressure heavy-duty distribution ratio for the impact of power supply capacity of the main factors. as shown in picture 2 :

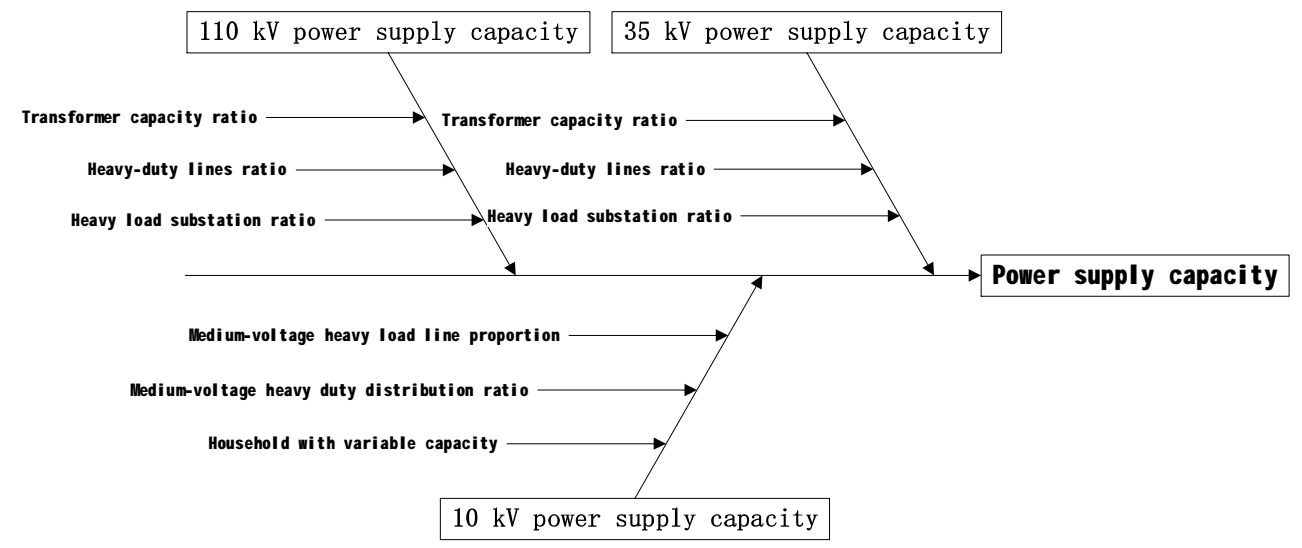

Figure 2 power supply capacity factors

\section{Grid structure}

The robustness of the grid structure can be described as the ability of the grid to withstand various disturbances while maintaining the stability of the system. The strength of the grid is a direct factor affecting the planning level of the distribution network in the area. The index is mainly composed of four sub-indicators, respectively, $110 \mathrm{kV}$ grid structure, $35 \mathrm{kV}$ power grid structure, $10 \mathrm{kV}$ power grid structure and $0.4 \mathrm{kV}$ power grid structure. Of which $10 \mathrm{kV}$ or more grid, single-line single variable ratio, $\mathrm{N}-1$ pass rate for the main factors affecting the structure of the grid. 10 kilovolt power grid, the average power supply radius of medium voltage line, medium pressure line connection rate, medium voltage line station between the contact rate and the pressure line $\mathrm{N}-1$ pass rate for the main factors affecting the power grid structure. The average power supply radius of low voltage lines in $0.4 \mathrm{kV}$ grid is the main factor affecting the structure of power grid. As shown in Figure 3: 


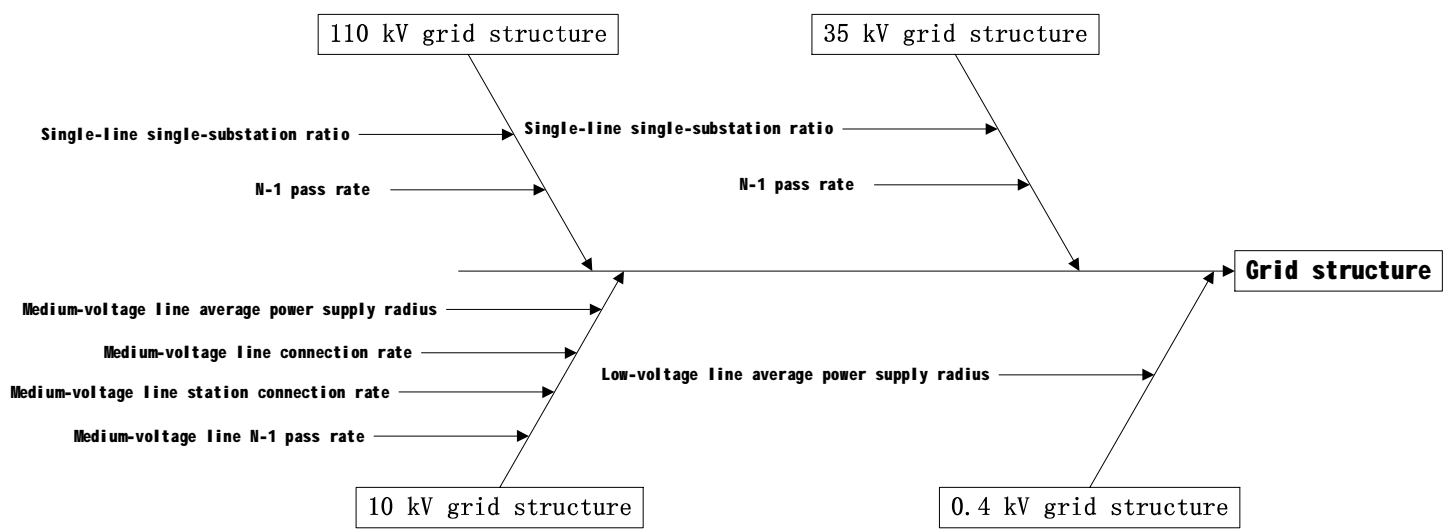

\section{Power supply quality}

Figure 3 factors affecting the power grid structure

The quality of the power supply marks the ability and degree of the grid to provide qualified and reliable power. Including voltage quality and power supply reliability in two aspects. The main influencing factors of voltage quality are "low voltage" user occupancy ratio and integrated voltage pass rate. As shown in Figure 4:

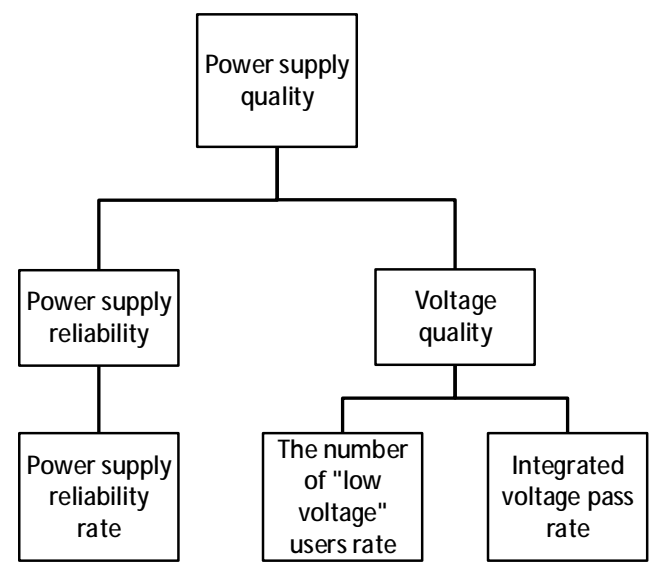

Figure 4 Power supply content contains content

\section{Equipment level}

The equipment level of the power grid is the symbol of the advanced nature of the power grid. It is an important index of the quality of the power grid planning. The equipment level of the distribution network is mainly reflected in the equipment of $10 \mathrm{kV}$, among which the high insulation distribution ratio and the medium voltage overhead line The most important influencing factor. As shown in Figure 5:

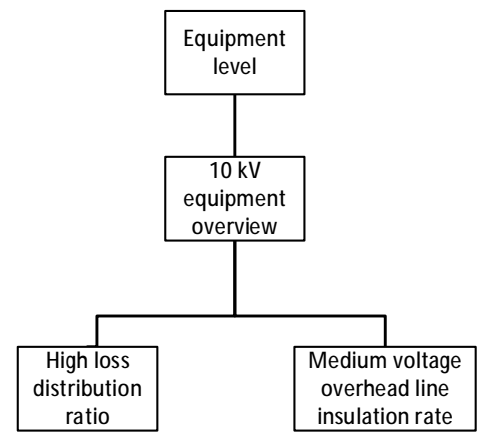

\section{Grid efficiency}

Figure 5 Level of equipment content included

Grid efficiency is an important comprehensive technical and economic index of electric power enterprises. The quality of distribution network is mainly reflected in the power loss, that is, the real-time line loss qualification rate of $10 \mathrm{kV}$ distribution network, which directly affects the power enterprises economic benefits. 


\section{Distribution network planning quality indicators}

According to the previous analysis and summary, and combined with the fuzzy analytic hierarchy process, the final distribution network planning quality indicators as shown in Table 1.

Tab.1 Distribution network planning quality index

\begin{tabular}{|c|c|c|c|}
\hline Numble & Level 1 indicators & Level 2 indicators & Level 3 indicators \\
\hline 1 & \multirow{9}{*}{$\begin{array}{l}\text { Power supply } \\
\text { capacity }\end{array}$} & \multirow{3}{*}{$\begin{array}{l}110 \mathrm{kV} \text { power supply } \\
\text { capacity }\end{array}$} & 110kV Transformer capacity ratio \\
\hline 2 & & & $110 \mathrm{kV}$ Heavy-duty lines ratio \\
\hline 3 & & & $110 \mathrm{kV}$ Heavy load substation ratio \\
\hline 4 & & \multirow{3}{*}{$\begin{array}{l}35 \mathrm{kV} \text { power supply } \\
\text { capacity }\end{array}$} & $35 \mathrm{kV}$ Transformer capacity ratio \\
\hline 5 & & & $35 \mathrm{kV}$ Heavy-duty lines ratio \\
\hline 6 & & & $35 \mathrm{kV}$ Heavy load substation ratio \\
\hline 7 & & \multirow{3}{*}{$\begin{array}{l}10 \mathrm{kV} \text { power supply } \\
\text { capacity }\end{array}$} & 10kV Transformer capacity ratio \\
\hline 8 & & & 10kV Heavy-duty lines ratio \\
\hline 9 & & & Household with variable capacity \\
\hline 10 & \multirow{3}{*}{$\begin{array}{l}\text { Power supply } \\
\text { quality }\end{array}$} & $\begin{array}{l}\text { Power supply } \\
\text { reliability }\end{array}$ & Power supply reliability rate \\
\hline 11 & & \multirow[b]{2}{*}{ Voltage quality } & The number of "low voltage" users rate \\
\hline 12 & & & Integrated voltage pass rate \\
\hline 13 & \multirow{9}{*}{$\begin{array}{l}\text { Power grid } \\
\text { structure }\end{array}$} & $110 \mathrm{kV}$ grid structure & $\begin{array}{c}\text { 110kV Single-line single-substation } \\
\text { ratio }\end{array}$ \\
\hline 14 & & & $110 \mathrm{kV} \mathrm{N}-1$ pass rate \\
\hline 15 & & \multirow[t]{2}{*}{$35 \mathrm{kV}$ grid structure } & $35 \mathrm{kV}$ Single-line single-substation ratio \\
\hline 16 & & & $35 \mathrm{kV} \mathrm{N}-1$ pass rate \\
\hline 17 & & \multirow[t]{4}{*}{$10 \mathrm{kV}$ grid structure } & $\begin{array}{l}\text { Medium-voltage line average power } \\
\text { supply radius }\end{array}$ \\
\hline 18 & & & Medium-voltage line connection rate \\
\hline 19 & & & $\begin{array}{l}\text { Medium-voltage line station connection } \\
\text { rate }\end{array}$ \\
\hline 20 & & & Medium-voltage line N-1 pass rate \\
\hline 21 & & $0.4 \mathrm{kV}$ grid structure & $\begin{array}{c}\text { Low-voltage line average power supply } \\
\text { radius }\end{array}$ \\
\hline 22 & \multirow[t]{2}{*}{ Equipment level } & \multirow{2}{*}{$\begin{array}{c}10 \mathrm{kV} \text { equipment } \\
\text { overview }\end{array}$} & High loss distribution ratio \\
\hline 23 & & & $\begin{array}{l}\text { Medium voltage overhead line } \\
\text { insulation rate }\end{array}$ \\
\hline 24 & Grid efficiency & Power loss & $\begin{array}{l}\text { 10kV Distribution line real-time line } \\
\text { loss qualification rate }\end{array}$ \\
\hline
\end{tabular}

One of the indicators for the power supply capacity, power supply quality, power supply reliability, grid efficiency, equipment level, power grid structure of the five indicators, the secondary indicators for the $110 \mathrm{kV}$ power supply capacity, voltage quality and other 11 indicators, three indicators for the change Capacitance load ratio, power supply reliability and other 24 indicators. The rationality of the indicators directly affects the evaluation effect. The structure of this paper is a three-tier structure with good integrity and adaptability, compact structure and high degree of aggregation. It can fully reflect the quality of distribution network planning. The indicators of the 
meaning of clear, the required value of the calculation by the data collected after the statistics obtained, the data source is simple, easy to calculate.

\section{Conclusion}

Because of the simple and unrealistic characteristics of the inherent distribution network, this paper presents the quality index of distribution network planning which is more applicable and practical, and can be used for longitudinal comparison and lateral comparison. It has the following characteristics:

(1) The key factors influencing the quality of distribution network are analyzed by using fish bone diagram analysis method, and then the Delphi expert consultation method and fuzzy analytic hierarchy process are used to determine the construction quality of distribution network planning.

(2) Compared with other evaluation indexes of distribution network, the quality index of distribution network planning is clear, and the planning level of distribution network is mainly evaluated, which covers $110 \mathrm{kV}, 35 \mathrm{kV}, 10 \mathrm{kV}, 0.4 \mathrm{kV}$ power grid, for the future direction of the distribution network to provide an important basis.

\section{Acknowledgments}

Corresponding author: Chenglei, Sun. (277129298@qq.com)

\section{References}

[1] Rong H U, Zhang Y, Fan C, et al. Post-evaluation index systems for distribution network planning[J]. East China Electric Power, 2007.

[2] Pan F, Chu L, Zhang M, et al. Assessment of Comprehensive Satisfaction Index of Connection Scheme in Planning Power Distribution Network[J]. Distribution \& Utilization, 2008.

[3] Qiang D J, Shou T, Zhu T M, et al. An evaluation index system and comprehensive evaluation model on high-voltage distribution network planning[J]. Power System Protection \& Control, 2013, 41(21):52-57.

[4] Lu X, Zhou Y, Zhang K M, et al. Research on Comprehensive Evaluation Index System for Distribution Network Planning Alternatives[J]. Advanced Materials Research, 2014, 960-961:1575-1581.

[5] Yan H M, Zhou H, Wang Z, et al. The establishment of Index System about Evaluation of Distribution Network and its application in Distribution Network Planning[J]. East China Electric Power, 2012, 32 Suppl 1(1 Supplement):99-101.

[6] Zheng Y, Kaike L I, Yang Y, et al. Study of Multi-objective Distribution Network Planning Based on the Contingency-load-loss Index[J]. Modern Electric Power, 2016. 